\title{
3-Stage Specially Structured Flow Shop Scheduling to Minimize the Rental Cost, Set Up Time Separated from Processing Time Including Transportation Time
}

\author{
Deepak Gupta \\ Prof. \& Head, Department of \\ Mathematics \\ M.M.University,Mullana, \\ Ambala,India
}

\author{
Shashi Bala \\ Department of Mathematics \\ M.M.University,Mullana, \\ Ambala,India
}

\author{
Payal Singla \\ Department of Mathematics \\ M.M.University,Mullana, \\ Ambala,India
}

\begin{abstract}
This article describes the development of a new heuristic algorithm which guarantees an optimal solution for specially structured flow shop problem with n-jobs,3- machines, to minimize the rental cost under specified rental policy in which set up times are separated from processes time, including transformation time. Further the processing times are not merely random but bear a well defined relationship to one another. Most of literature emphasized on minimization of idle time/ make span. But minimization of make span may not always lead to minimize rental cost of machines. Objective of this work is to minimize the rental cost of machines under a specified rental policy irrespective of make span.
\end{abstract}

Keywords: Specially structured flow shop scheduling. Rental policy, Processing time, Rental cost, Transportation time, Set up time, Utilization Time.

Mathematical subject classification: 90B30, 90B35.

\section{INTRODUCTION}

Scheduling is a decision making practice that is used on a regular basis in manu facturing and service industries. Its aim is to optimize one or more objectives with the allocation of resources to task over given time periods.

The time that a job spends on a machine include three phases viz setup, processing and removal. In the majority of investigation dedicated to production planning and scheduling, set up time considered to be negligible. But considering set up time separate from processing time have great impact on performance measure. As when there exists idle time on the second machine than the setup time for a job on a second machine can be performed prior to the completion time of this job on the first machine. Further the transportation times (loading time, moving time and unloading etc.) from one machine to another are also not negligible and therefore must be included in the job processing. However, in some application, transportation time have major impact on the performance measures considered for the scheduling problem so they need to considered separately. In a flow shop scheduling each job has the same routing throw machines and the sequence of operations is fixed. In a specially structured flow shop scheduling the data is not merely random but bears a well defined relation with one another. Gupta J.N.D [6] studied two stage specially structured flow shop scheduling problem. The basic study of flow shop scheduling was developed by Johnson [7]. Then work was developed by Singh and Deepak [15], Pandian \& Rajendran [12], Yoshida and Hitomi [17] etc. while considering various parameters. Maggu and Das [9] consider a two machine flow shop problem with transportation time of the jobs. Yoshida and Hitomi [17] studied the optimal two stage production scheduling with setup time separated from processing time. Gupta Deepak [5] et.al. Studied three stage specially structured flow shop scheduling problems to minimize the rental cost under a specified rental policy. Present Paper extends the study made by Gupta et al [5] by introducing the transportation time and setup time

In this paper we presents a specially structured flow shop scheduling model to minimize the utilization time of the machines and hence their rental cost under specified rental policy in which the setup times are separated from processing time, including transportation time. Most of the work emphasize on minimization of make span. Here we have discussed the algorithm which shows that minimization of make span does not always lead to minimize rental cost of machines.

\section{PRACTICAL SITUATION}

The majority of scheduling research assumes set up as negligible or part of processing time. While this assumption adversely affects solution quality for many applications which require explicit treatment of setup, includes work to prepare the machine for processing. This includes obtaining tools, positioning work-in-process material, return tooling, cleaning up, setting the required jigs and fixtures, adjusting tools and inspecting material and hence significant.

In our day to day working in factories and industrial production concern different jobs are processed on various machines. These jobs are required to process in machines $\mathrm{A}, \mathrm{B}, \mathrm{C},-----$ in a specified order. When the machine on which jobs are to be processed are planted at different places the transportation time ( which include loading time, moving time, and unloading time etc.) has a significant role in production concern. To established a new business or a manufacturing plant or a company one needs huge amount of money to purchase various machines, due to non liquidity of funds one cannot afford to buy all the expensive machinery prefer to take on rent. Renting is an affordable and quick solution for up gradation to new technology, saving working capital and best use of limited resources. 


\section{NOTATIONS}

$S \quad$ : Sequence of jobs $1,2,3, \ldots, \mathrm{n}$

$S_{k} \quad$ : Sequence obtained by applying Johnson's procedure, $\mathrm{k}=1,2,3,-----\mathrm{r}$.

$M_{j} \quad:$ Machine $\mathrm{j}, \mathrm{j}=1,2,3$.

$a_{i j} \quad$ : Processing time of $i^{\text {th }}$ job on machine $M_{j}$

$s_{i j} \quad:$ Set up time of $i^{\text {th }}$ job on machine $M_{j}$

$t_{i j}\left(S_{k}\right) \quad$ : Completion time of $i^{\text {th }}$ job on machine $M_{j}$

$t_{i l \rightarrow 2} \quad:$ Transportation time of $i^{\text {th }}$ job on $1^{\text {st }}$ machine to $2^{\text {nd }}$ machine.

$t_{i 2 \rightarrow 3} \quad:$ Transportation time of $i^{\text {th }}$ job from $2^{\text {nd }}$ machine to $3^{\text {rd }}$ machine

$U_{j}\left(S_{k}\right) \quad$ : Utilization time for which machine $M_{j}$ is required.

$R\left(S_{k}\right) \quad$ : Total rental cost for the sequence $S_{k}$ of all machine

$C_{j} \quad$ : Rental cost per unit time of $j^{\text {th }}$ machine.

\section{DEFINITION}

Completion time of $i^{\text {th }}$ job on machine $M_{j}$ is denoted by $t_{i j}$ and is defined as:

$t_{i j}=\max \left(\left(t_{i-1, l, j},+s_{i, j}\right) t_{i, j-1}+T_{i, j-l \rightarrow j}\right)+a_{i j} ; j \geq 2 . \mathrm{J}=2,3$

$t_{i l}=\max \left(\left(t_{i-1,2},+s_{i, 2}\right) t_{i, 1}+T_{i, 1 \rightarrow 2}\right)+a_{i 2}$

$t_{i 1}=\max \left(\left(t_{i-1,3},+s_{i, 3}, t_{i 2}+T_{i, 2 \rightarrow 3}\right)+a_{i 3}\right.$

\section{RENTAL POLICY (P)}

The machines will be taken on rent as and when they are required and are returned as and when they are no longer required.

\section{PROBLEM FORMULATION}

Let some job $i(i=1,2, \ldots \ldots \ldots, \mathrm{n})$ are to be processed on three machines $M_{j}(j=1,2,3)$ under the specified rental policy P. Let $a_{i j}$ be the processing time of $i^{\text {th }}$ job on $j^{\text {th }}$ machine $\mathrm{s}_{\mathrm{ij}}$ be the set time of its job on jth machine and ti and gi be transportation time of ith job from machine $M_{1}$ to $M_{2}$ and from machine $M_{2}$ to $M_{3}$ respectively such that either $\min \left(a_{i 1}+\right.$ $\left.\mathrm{t}_{\mathrm{i} 1 \rightarrow 2^{-}} \mathrm{s}_{\mathrm{i} 2}\right) \geq \max \left(\mathrm{a}_{\mathrm{i} 1}+\mathrm{t}_{\mathrm{i} 1 \rightarrow 2^{-}}-\mathrm{s}_{\mathrm{i} 1}\right)$

Or $\min \left(\mathrm{a}_{\mathrm{i} 3}+\mathrm{g}_{\mathrm{i} 2 \rightarrow 3}-\mathrm{s}_{\mathrm{i} 2}\right) \geq \max \left(\mathrm{a}_{\mathrm{i} 2}+\mathrm{t}_{\mathrm{i} 2 \rightarrow 3}-\mathrm{s}_{\mathrm{i} 3}\right)$ for all $\mathrm{i}, \mathrm{j}, \quad \mathrm{i} \neq \mathrm{j}$

Our aim is to find the sequence $\left\{S_{k}\right\}$ of jobs which minimize the rental cost of the machines while minimizing the utilization time of machines.

The mathematical model of the problem in matrix form can be stated as:

\begin{tabular}{|c|l|l|l|l|l|l|l|l|}
\hline Jobs & \multicolumn{2}{|l|}{$\begin{array}{l}\text { Machine } \\
\mathrm{M}_{1}\end{array}$} & $\begin{array}{l}\mathrm{t}_{\mathrm{i} \rightarrow 2} \\
\mathrm{t}_{\mathrm{i}}\end{array}$ & \multicolumn{2}{l|}{$\begin{array}{l}\text { Machine } \\
\mathrm{M}_{2}\end{array}$} & \multicolumn{2}{l|}{$\begin{array}{l}\mathrm{t}_{\mathrm{i} 2 \rightarrow 3} \\
\mathrm{~g}_{\mathrm{i}}\end{array}$} & \multicolumn{2}{l|}{$\begin{array}{l}\text { Machine } \\
\mathrm{M}_{3}\end{array}$} \\
\hline $\mathrm{i}$ & $a_{i 1}$ & $s_{i 1}$ & $t_{1}$ & $a_{i 2}$ & $s_{i 2}$ & $g_{1}$ & $a_{i 3}$ & $s_{i 3}$ \\
\hline 1 & $a_{11}$ & $s_{11}$ & $t_{2}$ & $a_{12}$ & $s_{12}$ & $g_{2}$ & $A_{13}$ & $s_{13}$ \\
\hline 2 & $a_{21}$ & $s_{21}$ & $t_{3}$ & $a_{22}$ & $s_{22}$ & $g_{3}$ & $A_{23}$ & $s_{23}$ \\
\hline 3 & $a_{31}$ & $s_{31}$ & $t_{4}$ & $a_{32}$ & $s_{32}$ & $g_{4}$ & $A_{33}$ & $s_{33}$ \\
\hline- & - & - & & - & - & & - & - \\
\hline $\mathrm{N}$ & $a_{n 1}$ & $s_{n 1}$ & $t_{n}$ & $a_{n 2}$ & $s_{n 2}$ & $g_{n}$ & $a_{n 3}$ & $s_{n 3}$ \\
\hline
\end{tabular}

Mathematically, the problem is stated as:

Minimize :

$$
\begin{gathered}
R\left(S_{k}\right)=\sum_{i=1}^{n} A_{i 1} \times c_{1}+u_{2}\left(S_{k}\right) \times c_{2}+u_{3}\left(S_{k}\right) \\
\times c_{3}
\end{gathered}
$$

Subject to constraint: Rental Policy (P) i.e. our objective is to minimize utilization time of machine and hence rental cost of machines.

\section{ALGORITHM}

Step 1: Check the following structural relationship. either $a_{i 1}+t_{i}-s_{i 2} \geq a_{i 2}+t_{i}-s_{i 2}$ for all $i, j i \neq j$ or $\mathrm{a}_{\mathrm{i} 2}+\mathrm{g}_{\mathrm{i}}-\mathrm{s}_{\mathrm{i} 2} \geq \mathrm{a}_{\mathrm{i} 2}+\mathrm{g}_{\mathrm{i}}-\mathrm{s}_{\mathrm{i} 3}$ or both

i.e all $\mathrm{i}, \mathrm{j}, \mathrm{i} \neq \mathrm{j}$

either $\left(\mathrm{a}_{\mathrm{i} 1}+\mathrm{t}_{\mathrm{i}}-\mathrm{s}_{\mathrm{i} 2}\right) \geq \max \left(\mathrm{a}_{\mathrm{i} 2}+\mathrm{t}_{\mathrm{i}}-\mathrm{s}_{\mathrm{i} 2}\right)$ or min $\left(a_{i 2}+g_{i}-s_{i 2}\right) \geq \max \left(a_{i 2}+g_{i}-s_{i 3}\right)$ or both for

If the conditions are satisfied then go to step 2 else modify the data.

Step 2: convert the problem into two machine problem. Let $\mathrm{G}$ and $\mathrm{H}$ be two fictitious machines having $\mathrm{G}_{\mathrm{i}}$ and $\mathrm{H}_{\mathrm{i}}$ as their processing times as:

$$
\begin{aligned}
& \mathrm{G}_{\mathrm{i}}=\mathrm{a}_{\mathrm{i} 1}+\mathrm{t}_{\mathrm{i}}+\mathrm{a}_{\mathrm{i} 2}+\mathrm{g}_{\mathrm{i}} \\
& \mathrm{H}_{\mathrm{i}}=\mathrm{t}_{\mathrm{i}}+\mathrm{a}_{\mathrm{i} 1}+\mathrm{g}_{\mathrm{i}}+\mathrm{a}_{\mathrm{i} 3}
\end{aligned}
$$

Step 3: obtain new reduced problem with processing time $G_{i}$ $\& H_{i}$ as follow: Then $G_{i}^{\prime}=G_{i}+\max \left(s_{i l}, s_{i 2}\right)$

$$
\mathrm{H}_{\mathrm{i}}^{\prime}=\mathrm{H}_{\mathrm{i}}-\mathrm{s}_{\mathrm{i} 3}
$$

Step 4: Obtain the optimal sequence $S_{\mathrm{i}}$ (Say) to minimize the make span by applying Johnson's [1954] algorithm on machine $\mathrm{G}$ and $\mathrm{H}$ with processing time $G_{i}^{\prime}$ and $\mathrm{H}_{\mathrm{i}}^{\prime}$ respectively

Step 5: Obtain other feasible sequences by putting $2^{\text {nd }}$, $3^{\text {rd }}, \ldots . . . n n^{\text {th }}$ jobs of sequence $S_{1}$ in first position respectively and all other jobs of $S_{1}$ in same order. 
Let the sequence be:

$\mathrm{S}_{2}, \mathrm{~S}_{3}-----\mathrm{S}_{\mathrm{n}}$

Step 6: Compute CT $\left(S_{k}\right)$; k=1,2-----r by making in - out table for sequences $S_{k}(k=1,2-----r)$.

Step 7: Calculate $\sum \mathrm{A}_{\mathrm{i} 1}, \mathrm{U}_{2}\left(\mathrm{~S}_{\mathrm{k}}\right) \& \mathrm{U}_{3}\left(\mathrm{~S}_{\mathrm{k}}\right)$ of $1^{\text {st }}, 2^{\text {nd }}$ and $3^{\text {rd }}$ machines respectively.

\section{Step 8: Calculate}

$$
R\left(S_{k}\right)=\sum_{i=1}^{n} A_{i 1} \times c_{1}+u_{2}\left(S_{k}\right) \times c_{2}+u_{3}\left(S_{k}\right) \times c_{3}
$$

Where $C_{1}, C_{2}$ and $C_{3}$ are the rental cost per unit time of machines $\mathrm{M}_{1}, \mathrm{M}_{2}$ and $\mathrm{M}_{3}$ respectively.

\section{NUMERICAL ILLUSTRATION}

Consider 5 jobs, 3 machines flow shop problem in which processing times, set up times with transportation times are given in the table. The rental cost per unit time for machines $\mathrm{M}_{1}, \mathrm{M}_{2}$ and $\mathrm{M}_{3}$ are 4 units, 5 units and 2 units respectively under the rental policy $\mathrm{P}$.

\begin{tabular}{|c|l|l|l|l|l|l|l|l|}
\hline Jobs & \multicolumn{2}{|l|}{$\begin{array}{l}\text { Machine } \\
\mathrm{M}_{1}\end{array}$} & $\begin{array}{l}\mathrm{t}_{\mathrm{i} \rightarrow 2} \\
\mathrm{t}_{\mathrm{i}}\end{array}$ & \multicolumn{2}{l|}{$\begin{array}{l}\text { Machine } \\
\mathrm{M}_{2}\end{array}$} & \multicolumn{2}{l|}{$\begin{array}{l}\mathrm{t}_{\mathrm{i} \rightarrow 3} \\
\mathrm{~g}_{\mathrm{i}}\end{array}$} & \multicolumn{2}{l|}{$\begin{array}{l}\text { Machine } \\
\mathrm{M}_{3}\end{array}$} \\
\hline $\mathrm{i}$ & $a_{i 1}$ & $s_{i 1}$ & $t_{i}$ & $a_{i 2}$ & $s_{i 2}$ & $g_{i}$ & $a_{i 3}$ & $s_{i 3}$ \\
\hline 1 & 15 & 6 & 4 & 18 & 2 & 1 & 50 & 3 \\
\hline 2 & 18 & 3 & 2 & 13 & 1 & 2 & 43 & 5 \\
\hline 3 & 30 & 2 & 1 & 20 & 4 & 5 & 60 & 1 \\
\hline 4 & 11 & 5 & 3 & 15 & 4 & 3 & 35 & 2 \\
\hline 5 & 9 & 1 & 5 & 25 & 2 & 1 & 65 & 4 \\
\hline
\end{tabular}

Table :2

Solution: As per step 1: The condition j

$$
\max \left(\mathrm{a}_{\mathrm{i} 2}+\mathrm{g}_{\mathrm{i}}-\mathrm{s}_{\mathrm{i} 3}\right) \leq \min \left(\mathrm{a}_{\mathrm{i} 2}+\mathrm{g}_{\mathrm{i}}-\mathrm{s}_{\mathrm{i} 2}\right) \text { for all } \mathrm{i}, \mathrm{j} \mathrm{i} \neq
$$

\section{Satisfies}

Thus as per step 2: Convert the problem in two machine problem $\mathrm{G}$ and $\mathrm{H}$ with $\mathrm{G}_{\mathrm{i}} \& \mathrm{H}_{\mathrm{i}}$ as the processing time as defined in step 2 .

Table : 3

\begin{tabular}{|l|l|l|l|l|l|}
\hline$i$ & 1 & 2 & 3 & 4 & 5 \\
\hline$G_{\mathrm{i}}^{\prime}$ & 44 & 38 & 60 & 37 & 42 \\
\hline $\mathrm{H}_{\mathrm{i}}^{\prime}$ & 70 & 55 & 85 & 54 & 52 \\
\hline
\end{tabular}

As per step 3: New reduced problem is :
Table : 4

\begin{tabular}{|c|c|c|}
\hline Jobs & $\begin{array}{c}\text { Machine } \\
\mathrm{M}_{1}\end{array}$ & $\begin{array}{c}\text { Machine } \\
\mathrm{M}_{2}\end{array}$ \\
\hline $\mathrm{i}$ & $\mathrm{G}_{\mathrm{i}}$ & $\mathrm{H}_{\mathrm{i}}$ \\
\hline 1 & 38 & 73 \\
\hline 2 & 35 & 60 \\
\hline 3 & 56 & 86 \\
\hline 4 & 32 & 56 \\
\hline 5 & 40 & 96 \\
\hline
\end{tabular}

As per step 4: Optimal sequence $S_{1}$ by Johnson method is

$$
\mathrm{S}_{1}: 4-2-5-1-3
$$

As per step 5: Other feasible sequence are

$$
\begin{aligned}
& S_{2}: 2-4-5-1-3 \\
& S_{3}: 5-4-2-1-3 \\
& S_{4}: 1-4-2-5-3 \\
& S_{5}: 3-4-2-5-1
\end{aligned}
$$

From in - out tables for these sequences we have:

For $\mathrm{S}_{1}: \mathrm{CT}\left(\mathrm{S}_{1}\right)=299$

$$
\sum_{i=1}^{n} A_{i 1}=98 ; \mathrm{U}_{2}\left(\mathrm{~S}_{1}\right)=105
$$

$$
\mathrm{U}_{3}\left(\mathrm{~S}_{1}\right)=267
$$

$$
\mathrm{R}\left(\mathrm{S}_{1}\right)=1451 .
$$

For $\mathrm{S}_{2}: \mathrm{CT}\left(\mathrm{S}_{1}\right)=302$;

$$
\sum_{i=1}^{n} A_{i 1}=98 ; \mathrm{U}_{2}\left(\mathrm{~S}_{2}\right)=101
$$

$$
\mathrm{U}_{3}\left(\mathrm{~S}_{2}\right)=267
$$

$\mathrm{R}\left(\mathrm{S}_{2}\right)=1431$.

For $\mathrm{S}_{3}: \mathrm{CT}\left(\mathrm{S}_{1}\right)=307$;

$$
\sum_{i=1}^{n} A_{i 1}=98 ; \mathrm{U}_{2}\left(\mathrm{~S}_{3}\right)=105
$$

$$
\mathrm{U}_{3}\left(\mathrm{~S}_{3}\right)=267
$$

$$
\mathrm{R}\left(\mathrm{S}_{3}\right)=1451 \text {. }
$$

For $\mathrm{S}_{4}: \mathrm{CT}\left(\mathrm{S}_{1}\right)=305$

$$
\sum_{i=1}^{n} A_{i 1}=98 ; \mathrm{U}_{2}\left(\mathrm{~S}_{4}\right)=100
$$

$$
\mathrm{U}_{3}\left(\mathrm{~S}_{4}\right)=267
$$

$\mathrm{R}\left(\mathrm{S}_{4}\right)=1426$.

For $\mathrm{S}_{5}: \mathrm{CT}\left(\mathrm{S}_{1}\right)=321$;

$$
\sum_{i=1}^{n} A_{i 1}=94 ; \mathrm{U}_{2}\left(\mathrm{~S}_{5}\right)=101
$$

$$
\mathrm{U}_{3}\left(\mathrm{~S}_{5}\right)=267
$$

$\mathrm{R}\left(\mathrm{S}_{5}\right)=1411$.

Therefore $\min \left\{\mathrm{R}\left(\mathrm{S}_{\mathrm{k}}\right)\right\}=\mathrm{R}\left(\mathrm{S}_{5}\right)=1411$ units and is for sequences $S_{5}$. Hence the sequences $S_{5}: 3-4-2-5-1$ is optimal sequences with min rental cost 1411 units although the total elapsed time is not min. 


\section{CONCLUSION}

The algorithm proposed here for specially structured three stage flow shop scheduling problem is more efficient as compared to the algorithm proposed by Johnson(1954) to find an optimal sequence to minimize the utilization time of the machines and hence their rental cost. The study may further be extended by considering various parameters like breakdown effect, job block criteria etc.

\section{REFERENCES}

[1] Anup (2002), "On two machine flow shop problem in which processing time assumes probabilities and there exists equivalent for an ordered job block", JISSOR, Vol. XXIII No. 1-4, pp. 41-44.

[2] Bagga P C (1969), "Sequencing in a rental situation", Journal of Canadian Operation Research Society, Vol.7, pp.152-153.

[3] Chander S, K Rajendra \& Deepak C (1992), "An Efficient Heuristic Approach to the scheduling of jobs in a flow shop", European Journal of Operation Research, Vol. 61, pp.318-325.

[4] Gupta Deepak \& Sharma Sameer (2011), "Minimizing rental cost under specified rental policy in two stage flow shop, the processing time associated with probabilities including breakdown interval and Job-block criteria", European Journal of Business and Management, Vol. 2, No. 3, pp.85-103.

[5] Gupta D., Sharma S. and Shashi B, "Specially Structured Three Stage Flowshop Scheduling to Minimize the Rental Cost", International Journal of Applied Physics and Mathematics, Vol. 2, No. 3, May 2012, pp. 156-158.

[6] Gupta J N D (1975), "Optimal Schedule for specially structured flow shop", Naval Research Logistic, Vol.22, No.2, pp. 255-269.
[7] Johnson, S.M.(1954), "Optimal two and three stage production schedule with set up times included", Naval Research Logistics Quart. 1(1), 61-68.

[8] M. Dell'Amico, Shop problems with two machines and time lags, Oper. Res. 44 (1996) 777-787.

[9] Maggu P L and Das G (1977), "Equivalent jobs for job block in job scheduling", Opsearch, Vol. 14, No.4, pp. 277-281.

[10] Narian L Bagga P C (2005), "Two machine flow shop problem with availability constraint on each machine", JISSOR, Vol. XXIV 1-4, pp.17-24.

[11] Narian,L. \& Bagga, P.C.(1998), “Minimizing hiring cost of machines in $\mathrm{n} \times$ 3flow shop problem", XXXI Annual ORSI Convention and International Conference on Operation Research and Industry, Agra[India].

[12] Pandian \& Rajendran (2010), "Solving Constraint flow shop scheduling problems with three machines", Int. J. Contemp. Math. Sciences, Vol.5, No. 19, pp.921-929.

[13] Singh T P (1985), “On $n \times 2$ shop problem involving job block. Transportation times and Break-down Machine times", PAMS, Vol. XXI , pp.1-2.

[14] Singh T P, K Rajindra \& Gupta Deepak (2005), “Optimal three stage production schedule the processing time and set times associated with probabilities including job block criteria", Proceedings of National Conference FACM-2005,pp. 463-492.

[15] Singh, T P, Gupta Deepak (2005), "Minimizing rental cost in two stage flow shop, the processing time associated with probabilities including job block", Reflections de ERA, Vol 1, No.2, pp.107-120.

[16] Szware W (1977), "Special cases of the flow shop problems", Naval Research Logistic, Vol.22, No.3, pp 483-492. 